\title{
The "no-dissection" technique is safe for reoperative aortic valve replacement with a patent left internal thoracic artery graft
}

\author{
Tsuyoshi Kaneko, MD, Foeke Nauta, MS, Wernard Borstlap, MS, Siobhan McGurk, BSc,
} James D. Rawn, MD, and Lawrence H. Cohn, MD

\begin{abstract}
Objective: Management of a patent left internal thoracic artery graft during reoperation is controversial. The "no-dissection" technique avoids dissection and clamping of the left internal thoracic artery graft, and myocardial protection is achieved using adjunctive systemic hypothermia and hyperkalemia. We compared the postoperative outcomes after isolated reoperative aortic valve replacement in patients with previous coronary artery bypass grafting with a patent left internal thoracic artery graft using a no-dissection technique with the outcomes of patients with previous coronary artery bypass grafting without a left internal thoracic artery graft.
\end{abstract}

\begin{abstract}
Methods: The outcomes were analyzed for patients who underwent isolated reoperative aortic valve replacement with previous coronary artery bypass grafting from January 1, 2002, to June, 30, 2011. Patency of the left internal thoracic artery was confirmed using either coronary angiography or computed tomography angiography. The patent left internal thoracic artery group did not undergo dissection or clamping of the left internal thoracic artery graft, and myocardial protection was obtained using systemic hypothermia and hyperkalemia. The no left internal thoracic artery group underwent isolated aortic valve replacement with previous coronary artery bypass grafting but had no left internal thoracic artery graft.
\end{abstract}

Results: A total 174 patients were identified for the patent left internal thoracic artery group and 26 for the no left internal thoracic artery group. The perfusion and crossclamp times were similar. No differences were seen between the 2 groups in operative mortality $(6.9 \%$ vs $7.7 \%, P=1.00)$. The complication rates were similar, and the peak creatine kinase-MB values within 24 hours of surgery were not significantly different between the 2 groups (median, 27.4 vs $29 \mu / \mathrm{mL} ; P=.72$ ).

Conclusions: Reoperative aortic valve replacement in patients with previous coronary artery bypass grafting and a patent left internal thoracic artery graft can be performed safely without dissection or clamping of the left internal thoracic artery using systemic hyperkalemia and hypothermia. We believe this method prevents unnecessary injury during dissection of the left internal thoracic artery graft. (J Thorac Cardiovasc Surg 2012;144:1036-41)

A left internal thoracic artery (LITA) to left anterior descending artery (LAD) graft has become the standard of practice, given its improved survival and superb long-term patency. ${ }^{1}$ Reoperation in cardiac surgery in a patient with a previous LITA to LAD graft is challenging for surgeons because of the specific consideration for myocardial protection and prevention of LITA graft injury. In aortic valve replacement (AVR), aortic crossclamping is required, unless hypothermic circulatory arrest is used. The most commonly used strategy for myocardial protection in the case of a patent LITA graft has been resternotomy, dissection of the

From the Department of Cardiac Surgery, Brigham and Women's Hospital, Boston, Mass.

Disclosures: Authors have nothing to disclose with regard to commercial support.

Read at the 38th Annual Meeting of The Western Thoracic Surgical Association, Maui, Hawaii, June 27-30, 2012.

Received for publication May 23, 2012; revisions received July 13, 2012; accepted for publication July 26, 2012; available ahead of print Aug 22, 2012.

Address for reprints: Lawrence H. Cohn, MD, Department of Cardiac Surgery, Brigham and Women's Hospital, 75 Francis St, Boston, MA (E-mail: 1cohn@ partners.org).

$0022-5223 / \$ 36.00$

Copyright (c) 2012 by The American Association for Thoracic Surgery

http://dx.doi.org/10.1016/j.jtcvs.2012.07.057
LITA graft, and occlusion of the graft after aortic clamping, followed by cardioplegic arrest. The proposed advantage is reducing cardioplegia washout in the LITA territory while maximizing myocardial protection. ${ }^{2}$ However, dissection of the LITA graft carries a risk of injury, with a reported risk of injury of up to $5.3 \%$ and mortality of up to $50 \%$. $^{3}$

Another strategy is to perform reoperative surgery without dissection of the LITA graft and to protect the myocardium by induction of moderate to deep hypothermia (to $20^{\circ} \mathrm{C}$ ), systemic hyperkalemia, and cardioplegia.

The purpose of the present study was to evaluate the safety of the latter "no-dissection technique" in patients undergoing reoperative aortic valve surgery with previous coronary artery bypass grafting (CABG) and a patent LITA graft.

\section{METHODS \\ Patient Population}

We studied patients who had undergone isolated reoperative AVR with previous CABG from January 1, 2002, to June 30, 2011. Patients with concomitant coronary and/or valve surgery or an occluded or dissected LITA were excluded. We classified patients into either the patent LITA group 


\section{Abbreviations and Acronyms \\ AVR = aortic valve replacement \\ $\mathrm{CABG}=$ coronary artery bypass grafting \\ $\mathrm{CK}-\mathrm{MB}=$ creatine kinase-MB \\ $\mathrm{LAD}=$ left anterior descending artery \\ LITA $=$ left internal thoracic artery}

or the no-LITA group to compare the outcomes. Patency of the LITA was confirmed using either preoperative coronary angiography or computed tomography angiography. All preoperative data, in-hospital outcomes, and postdischarge outcomes were collected from Brigham and Women's Hospital patient medical records and cardiac surgery database using the Society of Thoracic Surgeons definition and criteria. The present study was approved by the institutional review board of Brigham and Women's hospital. Patient consent was waived by the institutional review board.

\section{Operative Technique}

All the reviewed operations were performed using median sternotomy, upper hemisternotomy, or right thoracotomy. The cannulation strategy was selected on a case-by-case basis. In general, aortic cannulation and right atrial cannulation with dual-stage venous cannula was performed. However, in most cases, a femoral or axillary artery and femoral vein were dissected and cannulated to prepare for emergent need of cardiopulmonary bypass. Cardiopulmonary bypass was instituted in most patients before resternotomy to protect the patent LITA graft. Vacuum assistance for venous drainage was routinely applied. Access for antegrade or retrograde or both antegrade and retrograde cardioplegia was obtained. The patent LITA group did not undergo dissection or clamping of the LITA graft, and myocardial protection was obtained using moderate to deep systemic hypothermia $\left(20^{\circ} \mathrm{C}-28^{\circ} \mathrm{C}\right)$ and hyperkalemia, in addition to antegrade and/or retrograde cardioplegia. Hyperkalemia was obtained first by giving $40 \mathrm{mEq}$ of potassium chloride to a pump. Next, the goal of a potassium level greater than $6 \mathrm{mEq} / \mathrm{L}$ but less than $7 \mathrm{mEq} / \mathrm{L}$ was obtained by adding 10 to $20 \mathrm{mEq}$, as needed. Whenever cardiac activity was seen, potassium was added until the activity ceased. If collateral back flow from the coronary ostia obscured the operative field during replacement, the pump flows were temporary decreased to approximately 500 to $1500 \mathrm{~mL} / \mathrm{min}$ for several seconds to allow suture placement to the annulus. This was used in particular near the coronary ostium; otherwise, pump suction was placed near the ostium to provide a bloodless field. No attempts to dissect and clamp the LITA were made. The no-LITA group underwent isolated AVR with previous CABG, but had no LITA graft; therefore, no LITA dissection was involved. AVR was performed using a standard technique. Ultrafiltration was used to clear the high potassium level after release of the aortic crossclamp. De-airing in all cases was accomplished with transesophageal echocardiographic guidance, and the aortic root vent was maintained open until the patient was completely separated from cardiopulmonary bypass.

\section{Statistical Analysis}

The patient demographic data and operative and postoperative outcomes were collected prospectively during hospitalization and coded according to the standards of the Society of Thoracic Surgeons, version 2.52. The laboratory, echocardiographic, and transfusion data were extracted from the hospital electronic medical information systems.

Red blood cell use is presented as the percentage of cases transfused and median and interquartile range of units transfused. Operative mortality included any death in the hospital or within 30 days of surgery, if discharged. Readmissions included admission to any hospital within 30 days of discharge.

Normally distributed continuous variables are presented as the mean \pm standard deviation. Non-normally distributed continuous variables are presented as medians and interquartile ranges. Analyses of continuous variables was done using Student $t$ tests with Levine's homogeneity of variance or Mann-Whitney $U$ tests, as appropriate. Dichotomous variables are presented as the percentage of cases and number of cases and were evaluated using Fisher's exact test. All statistical analyses were done using SPSS, version 13.0 (SPSS, Chicago, Ill).

\section{RESULTS}

We identified 200 consecutive patients who underwent isolated reoperative AVR with previous CABG from January 1,2002 , to June 30,2011 . Of these 200 patients, 174 were included in the patent LITA group and 26 in the no-LITA group.

The patient characteristics are listed in Table 1. The results showed that the no-LITA group included older patients and more women but the other characteristics, including history of cardiovascular disease, peripheral vascular disease, renal failure, and cerebrovascular disease were similar. Cardiogenic shock at surgery was observed in 3 patients in the LITA group and none in the no-LITA group $(P=1.00)$. Two patients in the LITA group (1.2\%) underwent surgery on an emergent status versus none in the no-LITA group.

In the patent LITA group, there were 10 failed prosthetic valves ( 1 mechanical and 9 biologic) and 2 cases of prosthetic valve endocarditis. In the no-LITA group, there were 2 failed prosthetic valves (both biologic) and 1 case of prosthetic valve endocarditis.

The average number of patent grafts in the patent LITA group was 2.8 (range, 1-7) and in the no-LITA group was 2.6 (range, 2-6).

\section{Intraoperative Outcomes}

All patients underwent AVR using cardiopulmonary bypass and aortic crossclamping. The type of incisions used was upper hemisternotomy in $101(58.7 \%)$, right anterior thoracotomy in $1(0.6 \%)$, and full sternotomy $(41.5 \%)$ in 72 in the LITA group. In the no-LITA group, 12 patients had an upper hemisternotomy $(46.2 \%), 1$ patient a right anterior thoracotomy $(3.8 \%)$, and 13 patients a full sternotomy $(50.0 \%)$. For the arterial cannulation technique, aortic cannulation was used in $29(9.1 \%)$, femoral artery cannulation in $59(33.9 \%)$, and axillary artery cannulation in $86(49.4 \%)$ in the LITA group. In the no-LITA group, aortic cannulation was used in $10(38.4 \%)$, femoral artery cannulation in $4(15.4 \%)$, and axillary artery cannulation in $12(46.2 \%)$. For venous cannulation, 63 patients $(36.2 \%)$ in the LITA group and 9 patients $(34.6 \%)$ in the no-LITA group had femoral venous cannulation; all the others underwent standard atrial caval, 2-stage venous cannulation. No strict protocol was used in the choice of cannulation site. This was mainly decided by surgeon preference. The evaluated operative factors are listed in Table 2 . The perfusion time (median, 158 vs 145 minutes; $P=.10$ ) and crossclamp time (median, 77 vs 82 minutes; $P=.61$ ) 
TABLE 1. Patient characteristics

\begin{tabular}{lccc}
\hline $\begin{array}{c}\text { Preoperative } \\
\text { characteristics }\end{array}$ & $\begin{array}{c}\text { Patent } \\
\text { LITA }(\mathbf{n}=\mathbf{1 7 4})\end{array}$ & $\begin{array}{c}\text { No LITA } \\
(\mathbf{n}=\mathbf{2 6})\end{array}$ & $\boldsymbol{P \text { value }}$ \\
\hline Mean age (y) & $76.5 \pm 7.1$ & $79.4 \pm 5.8$ & $\leq .052$ \\
Women & $18.4(32)$ & $46.2(12)$ & $\leq .003$ \\
Family history of CAD & $24.1(42)$ & $19.2(5)$ & $\leq .804$ \\
Renal failure & $9.8(17)$ & $3.8(1)$ & $\leq .477$ \\
Preoperative creatinine & $1.3 \pm 0.7$ & $1.2 \pm 0.3$ & $\leq .407$ \\
CVA & $8.1(14)$ & $11.5(3)$ & $\leq .471$ \\
PVD & $32.2(56)$ & $19.2(5)$ & $\leq .254$ \\
Cardiovascular disease & $25.3(44)$ & $23.1(6)$ & 1.000 \\
Arrhythmia & $13.8(24)$ & $7.7(2)$ & $\leq .540$ \\
History of MI & $38.5(67)$ & $34.6(9)$ & $\leq .830$ \\
Cardiogenic shock & $1.7(3)$ & $0.0(0)$ & 1.000 \\
Emergent status & $1.2(2)$ & $0.0(0)$ & $\leq .405$ \\
Expected STS mortality & $6.9(12)$ & $6.4(2)$ & \\
\hline
\end{tabular}

Data presented as mean \pm standard deviation or percentages (numbers). LITA, Left internal thoracic artery; $C A D$, coronary artery disease; $C V A$, cerebrovascular disease; $P V D$, peripheral vascular disease; MI, myocardial infarction; STS, Society of Thoracic Surgeons.

were similar. No difference was seen in the usage of packed red blood cells. In the LITA group, 22 patients $(12.6 \%)$ underwent intra-aortic balloon pump insertion. Of these, 21 were intraoperative and 1 was inserted preoperatively. In the no-LITA group, $2(7.7 \%)$ underwent intra-aortic balloon pump insertion $(P=.746), 1$ preoperatively and 1 intraoperatively.

\section{Postoperative Outcomes}

The postoperative outcomes are summarized in Table 3. No differences were found between the 2 groups in operative mortality $(6.9 \%$ vs $7.7 \% ; P=1.00)$. When compared using the Society of Thoracic Surgeons risk algorithms, the observed versus expected mortality ratio was 1.0 and 1.2.

The complication rates, including reoperation for bleeding $(4.6 \%$ vs $3.8 \%, P=1.00)$, percentage of patients transfused $(58.6 \%$ vs $65.4 \%, P=.67)$, and intubation time (median, 12.0 vs 11.1 hours; $P=.40$ ), were similar. No

TABLE 2. Operative characteristics

\begin{tabular}{lccc}
\hline $\begin{array}{c}\text { Operative } \\
\text { characteristics }\end{array}$ & $\begin{array}{c}\text { Patent } \\
\text { LITA }(\mathbf{n}=\mathbf{1 7 4})\end{array}$ & $\begin{array}{c}\text { No LITA } \\
(\mathbf{n}=\mathbf{2 6})\end{array}$ & $\boldsymbol{P}$ value \\
\hline Perfusion time (min) & & & .103 \\
$\quad$ Median & 158 & 145 & \\
IQR & $131-204$ & $125-194$ & \\
Crossclamp time (min) & & & .616 \\
$\quad$ Median & 77 & 82 & \\
IQR & $63-98$ & $60-114$ & \\
Intraoperative IABP & $12.6(22)$ & $7.7(2)$ & .746 \\
Patients transfused with RBCs (n) & $19.5(34)$ & $23.1(6)$ & .610 \\
RBC units transfused (n) & & & .712 \\
$\quad$ Median & 3.0 & 3.0 & \\
IQR & $1-4$ & $2-4$ & \\
\hline
\end{tabular}

Data presented as median and IQR or percentages (numbers). LITA, Left internal thoracic artery; $I Q R$, interquartile range; $I A B P$, intra-aortic balloon pump; $R B C$, red blood cell.
TABLE 3. Postoperative outcomes of patent LITA group and no-LITA group

\begin{tabular}{lccr}
\hline \multicolumn{1}{c}{$\begin{array}{c}\text { Postoperative } \\
\text { outcomes }\end{array}$} & $\begin{array}{c}\text { Patent LITA } \\
(\mathbf{n}=\mathbf{1 7 4})\end{array}$ & $\begin{array}{c}\text { No LITA } \\
(\mathbf{n}=\mathbf{2 6})\end{array}$ & $\boldsymbol{P}$ value \\
\hline Peak CK-MB $\leq 24 \mathrm{~h}$ & & & .723 \\
$\quad$ Median & 27.4 & 29 & \\
IQR & $17-69$ & $21-38$ & \\
Peak CK-MB $\leq 72 \mathrm{~h}$ & & & .653 \\
$\quad$ Median & 28.5 & 29.6 & \\
IQR & $17-66$ & $21-38$ & \\
Reoperation for bleeding & $4.6(8)$ & $3.8(1)$ & 1.000 \\
Permanent stroke & $4.0(7)$ & $0.0(0)$ & .597 \\
Transfused with RBCs & $58.6(102)$ & $65.4(17)$ & .669 \\
ICU stay (h) & & & .549 \\
$\quad$ Median & 73.0 & 69.5 & \\
IQR & $38-119$ & $43-98$ & \\
Ventilation time (h) & & & .397 \\
Median & 12.0 & 11.1 & \\
IQR & $7-30$ & $7-8$ & \\
LOS (d) & & & .111 \\
Median & 9.0 & 7.0 & \\
IQR & $6-14$ & $7-8$ & \\
Operative mortality & $6.9(12)$ & $7.7(2)$ & 1.000 \\
Expected STS mortality & $6.9(12)$ & $6.4(2)$ & \\
Observed/expected ratio & 1.0 & 1.2 & \\
\hline
\end{tabular}

Data presented as median and IQR or percentages (numbers). LITA, Left internal thoracic artery; $C K-M B$, creatine kinase-MB; $I Q R$, interquartile range; $R B C$, red blood cell; $I C U$, intensive care unit; $L O S$, length of stay; STS, Society of Thoracic Surgeons.

difference was seen in the stroke rate or duration of intensive care unit stay.

Intraoperative injury to the LITA was encountered in 1 patient and was repaired immediately. This occurred during mediastinal dissection; no injuries to the LITA graft occurred during redo sternotomy.

We used postoperative creatine kinase (CK)-MB leakage as a measure of the adequacy of myocardial protection. The peak CK-MB values within 24 hours of surgery were not significantly different (median, 27.4 vs $29 \mu / \mathrm{mL}$; $P=.72$ ), nor were the peak CK-MB values within 72 hours (median, 28.5 vs $29.6 \mu / \mathrm{mL} ; P=.653$ ). No new $\mathrm{Q}$ waves on the electrocardiogram and no new asynergy on the echocardiogram were seen postoperatively among these patient groups. Also, no postoperative intra-aortic balloon pump use in either group.

\section{DISCUSSION}

The use of the LITA to LAD graft has become the standard of practice and has increased survival in the coronary artery populations. This has created a new patient population for cardiac surgeons constituting those previous coronary artery grafting and progressive valve disease that ultimately requires surgical intervention, especially with a patent LITA to LAD graft. Unlike mitral surgery or coronary artery disease, aortic valve disease requires 
crossclamping of the aorta unless circulatory arrest is used. The most common strategy in these patients is to perform resternotomy, dissect the LITA graft, and clamp the graft, with cardioplegia given to prevent washout in the LITA territory. This means that the border zones of perfused versus arrested myocardium are hypothetically at greater risk of ischemic injury. However, injury to the LITA graft during dissection can have serious consequences. The rate of injury has been reported to be $5 \%$ to $40 \%$, with perioperative mortality reported to be $9 \%$ to $50 \%{ }^{4-6}$

Several techniques during the initial surgery have been reported to prevent LITA injury during reoperation. These have included interposition of the lung between the chest wall and LITA, ${ }^{7}$ the use of polytetrafluoroethylene membrane to cover the LITA, ${ }^{8}$ and creating a slit in the pericardium to tuck the LITA away from posterior table of the sternum. ${ }^{9}$ A careful review of the computed tomography scan has been used to check for the relationship between previous clips on the pedicle and the posterior table of the sternum and has proved beneficial. ${ }^{10}$ Early institution of cardiopulmonary bypass during resternotomy allows easier dissection by decompression of the heart. ${ }^{11}$ Left lateral thoracotomy for lateral lesions to avoid sternotomy ${ }^{12}$ and offpump bypass to eliminate the need for LITA dissection ${ }^{13}$ has also been reported to prevent injury to the LITA. All these strategies can be used to reduce the risk of LITA injury during dissection. In our practice, we perform interposition of the lung, preoperative computed tomography, and early institution of cardiopulmonary bypass.

In the present report, we have documented the results with the "no-dissection technique." This method leaves the patent LITA graft open during aortic crossclamping, allowing the LITA graft to perfuse during aortic valve surgery. The unique feature in this method is the temperature discrepancy of the myocardial areas. The myocardium is protected by cardioplegia $\left(4^{\circ} \mathrm{C}\right)$, which is cooler than cardiopulmonary bypass $\left(20^{\circ} \mathrm{C}-28^{\circ} \mathrm{C}\right)$, but cardioplegia washout by the patent LITA graft causes the LAD territory to reach the same temperature as with cardiopulmonary bypass. Therefore, moderate to deep hypothermia is mandatory. In the beginning of the present study, we were cooling to $20^{\circ} \mathrm{C}$; however, other reports have confirmed safe protection with higher temperatures. ${ }^{14}$ Currently, our practice is to cool to $28^{\circ} \mathrm{C}$ and to cool further with the addition of hyperkalemia if uncontrollable cardiac activity occurs. In addition, systemic hyperkalemia to 6 to $7 \mathrm{mEq} / \mathrm{L}$ was obtained to maintain cardiac arrest. Although hypothetically systemic hyperkalemia can reduce vascular tone by affecting the potassium channels, this was not encountered during our experience. If blood returning from the coronary ostium obscures the field, we decrease the pump flow temporarily to allow suture placement. This technique is amenable to minimally invasive hemisternotomy for reoperative aortic valve surgery, ${ }^{15}$ in which dissection of the
LITA graft imposes a greater risk of injury owing to its limited field. We used both antegrade and retrograde cardioplegia with different strategies optimized to the individual patient findings. The access and cannulation strategy was surgeon dependent. The rate of hemisternotomy was similar in the 2 groups $(58.7 \%$ vs $46.2 \%)$. However, the nodissection group underwent more femoral cannulation $(33.9 \%$ vs $19.4 \%)$ and the no-LITA group had more aortic cannulation $(9.1 \%$ vs $38.4 \%)$. This was likely owing to surgeon selection of femoral artery cannulation in the case of emergency because the patients had a patent LITA and were thought to be at high risk.

Lytle and colleagues ${ }^{16}$ first described the concept of the no-dissection technique. Others have reported this technique to be safe and valid. Byrne and colleagues ${ }^{17}$ reported on 94 patients undergoing AVR with a patent LITA graft and found a perioperative mortality of $6.4 \%$. Smith and colleagues ${ }^{14}$ reported on 118 patients who underwent no dissection of the LITA and compared them with 88 patients in whom the LITA was dissected and showed no difference in mortality but a reduction in patent graft injury. There have also been reports using the no-dissection technique and performing AVR with a beating heart technique with good outcomes. ${ }^{18}$

Our study showed similar perfusion and crossclamp times with those of the control group. Also, no difference was found in mortality. Several predictors of mortality in reoperative surgery have been proposed, including age, low ejection fraction, and advanced New York Heart Association functional class, ${ }^{19,20}$ but we could not confirm these relationships. We used postoperative CK-MB leakage as a measure of the adequacy of myocardial protection, and the peak CK-MB values within 24 and 72 hours of surgery were not statistically different. Also, no ST changes were seen in these patients. However, we encountered 1 LITA injury with the "no-dissection" technique. This occurred during dissection of dense adhesions and the injury occurred at the previous LITA to LAD anastomosis. The injury was repaired primarily. The incidence of LITA injury was $5 \%$ in the report by Byrne and colleagues. ${ }^{17}$ Our report showed an even lower incidence of LITA injury $(0.6 \%)$, confirming the safety of the "no-dissection" technique.

Retrograde cardioplegia alone is used in reoperative cardiac surgery with promising outcomes. ${ }^{21}$ However, theoretically, the perfusion pressure in retrograde cardioplegia (average, $25-30 \mathrm{~mm} \mathrm{Hg}$ ) is lower than the systemic pressure during cardiopulmonary bypass (average, $60-70 \mathrm{~mm} \mathrm{Hg}$ ), which compromised myocardial protection in the patent LITA perfusion area. Therefore, we believe our technique with hypothermia and hyperkalemia combined with cardioplegia will provide better myocardial protection.

The present study had some limitations. First, this was a retrospective study. It did include the largest series of patients undergoing this technique; however, the statistical significance could not overcome the retrospective nature 
of the present study. Second, the comparison group was not ideal and the size of the group was small. The ideal group would be a patent LITA group that underwent dissection of the graft. We did find 6 patients who underwent LITA dissection during the study period; however, that would have been an even smaller comparison group with less value for statistical comparison. We had 1 LITA injury among these 6 patients who underwent LITA dissection. On the other hand, the comparison group who had previous CABG without a LITA graft will have complete myocardial protection through antegrade cardioplegia. Thus, no coronary blood flow originating distal to the aortic crossclamp is present to wash out the cardioplegia, and good cardioplegia perfusion to the LAD area is provided that will not be provided in patients with a dissected or patent LITA. That the CK-MB levels were comparable those in this wellprotected group indicates the safety of the no-dissection technique.

\section{CONCLUSIONS}

Patients undergoing AVR after CABG in the presence of a patent LITA are at high risk of injury. Although the common practice has been to dissect the graft and clamp to achieve full myocardial protection, there is a danger of graft injury during dissection. The "no-dissection" technique demonstrated no increase in mortality and morbidity and is an effective strategy using hypothermia and systemic hyperkalemia to counteract the cardioplegia washout effect.

\section{References}

1. Loop FD, Lytle BW, Cosgrove DM, Stewart RW, Goormastic M, Williams GW, et al. Influence of the internal mammary graft on 10- year survival and other cardiac events. N Engl J Med. 1986;314:1-6.

2. Mills NL, Everson CT, Hockmuth DR. Technical considerations for myocardial protection during the course of coronary artery bypass reoperation: the impact of functioning saphenous vein and internal mammary artery grafts. J Card Surg. 1991;6:34-40.

3. Gillinov AM, Casselman FP, Lytle BW, Blackstone EH, Parsons BS, Loop FD, et al. Injury to a patent left internal thoracic artery graft at coronary reoperation. Ann Thorac Surg. 1999;67:382-6.

4. Elami A, Laks H, Merin G. Technique for reoperative median sternotomy in the presence of patent left internal mammary artery graft. J Card Surg. 1994;9:123-7.

5. Coltharp WH, Decker MD, Lea JW, Petrasec MR, Glassford DM, Thomas CS, et al. Internal mammary artery graft at reoperation: risks, benefits and methods of preservation. Ann Thorac Surg. 1991;52:225-9.

6. Ivert TS, Ekestrom S, Peterffy A, Welti R. Coronary artery reoperations: early and late results in 101 patients. Scand J Thorac Cardiovasc Surg. 1988;22:111-8.

7. Fullerton DA, St Cyr JA, Fall SM, Whitman GJ. Protection of the patent internal mammary artery bypass graft from subsequent sternotomy. J Cardiovasc Surg (Torino). 1994;35:499-501.

8. Zehr KJ, Lee PC, Poston RS, Gillinov AM, Hruban RH, Cameron DE. Protection of the internal mammary pedicle with polytetrafluoroethylene membrane. J Card Surg. 1993;8:650-5.

9. Blanche C, Santibanez-Gallerani A. Technique to protect the internal mammary artery pedicle. Ann Thorac Surg. 1995;60:1824-5.

10. Aviram G, Sharony R, Kramer A, Nesher N, Loberman D, Ben-Gal Y, et al. Modification of surgical planning based on cardiac multidetector computed tomography in reoperative heart surgery. Ann Thorac Surg. 2005;79:589-95.

11. Cohn LH. Myocardial protection for reoperative cardiac surgery in acquired heart disease. Semin Thorac Cardiovasc Surg. 1993;5:162-7.
12. Byrne JG, Aklog L, Adams DH, Cohn LH, Aranki SF. Reoperative CABG using left thoracotomy: a tailored strategy. Ann Thorac Surg. 2001;71:196-200.

13. Mack MJ. Off-pump surgery and alternatives to standard operation in redo coronary surgery. J Card Surg. 2004;19:313-9.

14. Smith RL, Ellman PI, Thompson PW, Girotti ME, Mettler MA, Ailawadi G, et al. Do you need to clamp a patent left internal thoracic artery-left anterior descending graft in reoperative cardiac surgery? Ann Thorac Surg. 2009;87:742-7.

15. Tabata M, Khalpey Z, Shekar PS, Cohn LH. Reoperative minimal access aortic valve surgery: minimal mediastinal dissection and minimal injury risk. J Thorac Cardiovasc Surg. 2008; $136: 1564-8$.

16. Lytle BW, McElroy D, McCarthy P, Loop FD, Taylor PC, Goormastic M, et al. Influence of arterial coronary bypass grafts on the mortality in coronary reoperations. J Thorac Cardiovasc Surg. 1994;107:675-83.

17. Byrne JG, Karavas AN, Filsoufi F, Mihaljevic T, Aklog L, Adams D, et al. Aortic valve surgery after previous coronary artery bypass grafting with functioning internal mammary artery grafts. Ann Thorac Surg. 2002;73:779-84.

18. Battellini R, Rastan AJ, Fabricius A, Moscoso-Luduena M, Lachmann N, Mohr FW. Beating heart aortic valve replacement after previous coronary artery bypass surgery with a patent internal mammary artery graft. Ann Thorac Surg. 2007;83:1206-9.

19. Lytle BW, Cosgrove DM, Taylor PC, Gill CC, Goormastic M, Golding LR, et al. Reoperations for valve surgery: perioperative mortality and determinants of risk for 1,000 patients, 1958-1984. Ann Thorac Surg. 1986;42:632-43.

20. Sundt TM III, Murphy SF, Barzilai B, Schuessler RB, Mendeloff EN, Huddleston $\mathrm{CB}$, et al. Previous coronary artery bypass grafting is not a risk factor for aortic valve replacement. Ann Thorac Surg. 1997;64:651-8.

21. Borger MA, Rao V, Weisel RD, Floh AA, Cohen G, Feidel CM, et al. Reoperative coronary bypass surgery: effect of patent grafts and retrograde cardioplegia. $J$ Thorac Cardiovasc Surg. 2001;121:83-90.

\section{Discussion}

Dr Richard Shemin (Los Angeles, Calif). Thank you very much for a beautiful presentation and for bringing this very large series to our forum today.

Obviously, the topic is driven by the desire, number 1, to totally eliminate any injury to the LITA and, number 2, to try to increase the number of minimally invasive or minimal access approaches in the re-do CABG population who come for valve replacement. You showed some data at the risk of injury to the LITA and you quoted data from the 1980s and 1990s showing it was $40 \%$ to $50 \%$ and in the modern era it may be $5 \%$, but I personally submit that, if we look at the re-do CABG rate in which patent LITAs are almost routine, that the rate of $5 \%$ is still an overestimate, particularly with routine CT scanning to really know whether or not you have a thoracic artery that is stuck behind the sternum. I think the major contributions of your paper are the size of the series, 176 patientsthere are other series in the literature, I think this is the largest one; the fact that half these patients did have a mini-sternotomy, which is a very important part of the series; your good outcomes, which obviously is very important; and your ability to show that leaving the LITA open actually allowed decent or good myocardial protection.

I have a few concerns and a few questions for you.

First of all, when I review a series in which the treatment group is 174 patients and 26 patients in the control group, I really worry whether that is an adequate comparison and whether or not any of the statistics between the 2 groups are really legitimate. I am not sure you are really powered to do any comparison between the 2 groups.

You do not tell us in your presentation or in the manuscript whether or not there was left anterior descending disease in those 26 patients and whether or not they were saphenous vein bypasses. Can you comment on that? 
Dr Kaneko. We did review all the coronary angiograms and the computed tomography angiography before the procedure as we mentioned. In those data, whenever we find coronary artery disease that actually went to a repair, those patients were excluded. That was 1 of the factors why this comparison group was small. I think your suggestion that 26 patients is a very small comparison group is totally valid. My ideal comparison group would have been a dissected LITA group and compare those 2 with showing a better outcome in the no-dissection technique. However, in our institution, this technique is standard and I was only able to find 6 patients with a dissected LITA. This was an even lower number to compare. That is why we used this as a comparison group.

Dr Shemin. Another interesting data point that came to my attention was the fact that the cardiopulmonary bypass time in the 2 groups was similar. I cannot understand that if in half the patients you cannulated the groin went on to bypass before opening the chest, cooled to 20 degrees, and then had to rewarm, how could you have a similar time on bypass to a group of patients in whom you just opened the chest? I assume that the cooling was a routine 30 to 34 degrees, so the warming and cooling time would obviously not be anywhere as long.

Dr Kaneko. The initiation of cardiopulmonary bypass was completely surgeon dependent. In the data before 2002, it was our standard practice to initiate a cardiopulmonary bypass before doing the resternotomy. In the recent patients that at least I have seen, we perform a sternotomy under no cardiopulmonary bypass; however, they are cannulated and, as soon as the mediastinal dissection gets difficult, we started cooling, which like you said might take time, but that will eliminate some of the time that is used in the sternotomy time. Also, there was a slight difference, although statistically nonsignificant (5 minute shorter time), in the crossclamp time. Our belief is that, hopefully, shorter crossclamp time is contributing to that as well.

Dr Shemin. Okay. I do not quite buy it but-I mean it usually takes 45 minutes to an hour to cool somebody to 20 degrees and sometimes at least 1-and-a-half to twice as long to rewarm them, so I think, again, the comparison group is somewhat detracting from the message of the good results in your study.

The same thing with adequacy and myocardial protection: In your manuscript, you mentioned that 22 patients, or $12.5 \%$, required a balloon pump and 21 of those 22 were put in intraoperatively whereas, in the "comparison group," it was only 2 patients or $7 \%$. Were these balloons put in for high-dose inotropes and power failure, suggesting that maybe the myocardial protection despite your creatine phosphokinase data were not quite as good as you are leading us to believe?

Dr Kaneko. There were 2 patients who had a preoperative intraaortic balloon pump, but, yes, there are more patients who received intra-aortic balloon pump during the case in the no-dissection group. We do not have a good explanation for that. We were trying to look at the inotropes along with the balloon pump to see if that will correlate the need and possibly reflect the myocardial protection, but those values were not really available. That is one of the weaknesses of the findings that we had.

Dr Shemin. You also mentioned in the manuscript that very often with the thoracic artery being patent that placing the sutures in the annulus can sometimes be obscured particularly in the left main coronary artery because of backflow, and you would have to go down to flow rates between 500 and 1500. Can you say how often that was done and for what period of time because the stroke rate was $2.2 \%$, which probably is quite acceptable but I am just interested in how much low-flow perfusion was necessary just to technically perform the suturing.

Dr Kaneko. When we placed the suction right at the coronary ostium, unless you are putting a stitch right around that area, it is usually pretty visible. I think the visual field is okay. We only have to stop the pump maybe once or twice if the stitch is right at the coronary ostium on the left side. That has been the usual case that I have seen.

Dr Shemin. And my last question-I think everyone in the audience understands hypothermia, but tell us a little bit about hyperkalemia, systemic hyperkalemia: To what level, how did you achieve it, what do you do with people with renal failure? Is there a contraindication to this technique?

Dr Kaneko. How we usually do it is we place $40 \mathrm{mEq}$ of potassium chloride into the pump. Our goal is above 6 but not going over 7. Usually, after $40 \mathrm{mEq}$, we were able to maintain that level. The only time that we had to give further potassium was when the myocardium starting moving. When there is activity, we usually add 10 to $20 \mathrm{mEq}$ to control that, and that has worked pretty well. I did not include this in the slides but we had 3 patients in the no-dissection group who had dialysis after surgery, which equals about $2 \%$ in the whole population. That is comparable to some of the other groups that we have studied, so I do not think there is an increase in the renal failure patients and, usually after the surgery at the end of a case using ultra-filtration, potassium level is around 5. After diuresis by cardiopulmonary bypass, their potassium level goes to a normal level within 24 hours.

Dr Shemin. You certainly have all that warming time to get that potassium back down to normal.

Congratulations on a nice presentation and I thank the Western for the opportunity to discuss this paper.

Dr John Ikonomidis (Charleston, SC). I enjoyed the presentation a lot. I have a question about the incidence of ventricular fibrillation in the no-dissection group.

I did not catch it in your presentation but did you record the incidence of ventricular fibrillation, how long it occurred? You did not give us any information about administration of cardioplegia in terms of frequency. In the no-dissection group, did you give cardioplegia more often to try and counteract that? Also, what about administration of antiarrhythmics in those patients? Could you comment on those issues?

Dr Kaneko. The cardioplegia technique was surgeon preference and about half of the patients received antegrade and half that received antegrade and retrograde.

Ventricular fibrillation was seen especially when the patient was hypothermic. At around 20 degrees there is usually no myocardial activity and at around 25 or 26 , when we see a fibrillation, we add potassium to stop that activity at that time.

As far as antiarrhythmics, it is not our routine to use them in our institutions. However, if we see a ventricular tachycardia, we do give lidocaine in the pump and that is our standard practice, yes. 